\title{
Health Impacts of Heat in a Changing Climate: How Can Emerging Science Inform Urban Adaptation Planning?
}

\author{
E. P. Petkova • H. Morita • P. L. Kinney
}

Published online: 5 April 2014

(C) Springer International Publishing AG 2014

\begin{abstract}
Extreme heat is one of the most important global causes of weather-related mortality, and climate change is leading to more frequent and intense heat waves. Recent epidemiologic findings on heat-related health impacts have reinforced our understanding of the mortality impacts of extreme heat and have shown a range of impacts on morbidity outcomes, including cardiovascular, respiratory, and mental health responses. Evidence is also emerging on temporal trends towards decreasing exposure-response, probably reflecting population adaptation. Many cities are actively engaged in the development of heat adaptation plans to reduce future health impacts. Epidemiologic research into the evolution of local heat-health responses over time can greatly aid in planning heat adaptation, prevention of adverse health outcomes among vulnerable populations, and the evaluation of new interventions. Such research will be facilitated by the formation of research partnerships involving epidemiologists, climate scientists, and local stakeholders.
\end{abstract}

Keywords Heat - Extreme temperature $\cdot$ Climate $\cdot$ Health . Mortality $\cdot$ Morbidity $\cdot$ Vulnerable populations $\cdot$ Adaptation strategy

\author{
E. P. Petkova $\cdot$ H. Morita $\cdot$ P. L. Kinney $(\bowtie)$ \\ Mailman School of Public Health, Columbia University, 722 West \\ 168th Street, New York, NY 10019, USA \\ e-mail: plk3@columbia.edu \\ E. P. Petkova \\ e-mail: epp21096@columbia.edu \\ H. Morita \\ e-mail: hm2487@columbia.edu
}

\section{Introduction}

Heat is responsible for more fatalities per year on average than any other weather-related hazard in the USA, according to the National Weather Service [1]. Furthermore, heat-related mortality and morbidity are the most well understood, measureable, and potentially important impacts of climate change on human health [2]. Global mean temperatures have been rising at a rate of about $0.2{ }^{\circ} \mathrm{C}$ for the past few decades and are expected to rise even more rapidly for the next few decades, regardless of the stringency of future greenhouse gas emission reduction policies [3].

Urban areas are thought to be particularly vulnerable to the impacts of heat, since they concentrate large numbers of vulnerable people (e.g., elderly, infirm) in settings where ambient temperatures are often higher than suburban and rural areas. Many cities contain relatively high proportions of older housing stock that may be less well adapted to hot weather. In addition, populations are aging and the prevalence of obesity in adults has been increasing. Being elderly, obese, and/or diabetic are all risk factors for heat-related mortality [4-6].

In the face of these challenges, many cities are developing strategies to build greater resilience against heatrelated health impacts, often in the context of overall climate adaptation plans. Climate adaptation planning efforts usually involve an assessment of the vulnerability of infrastructure and population to climate extremes and the development of plans to reduce the impacts therefrom. The overall goal of the present paper is to review the recent epidemiologic literature on heat-related health impacts, and to evaluate the utility of the emerging knowledge base for use in adaptation planning related to heat and health. 


\section{Health Impacts of Heat}

\section{Findings from Prior Reviews}

A number of prior literature reviews have examined the impacts of heat on morbidity and mortality. For example, Basu and Samet reviewed studies published since 1970 and found consistent evidence of increased mortality during heat waves, as well as positive associations between ambient exposures to heat in general and increased mortality, particularly among the elderly [5]. Individuals with pre-existing medical conditions, particularly cardiovascular and respiratory, as well as those of low socioeconomic status, were reported to be at increased risk. In a follow-up study, based on evidence from the epidemiologic studies published since the previous review, Basu confirmed these findings and also concluded that the mortality effects of heat have been observed not only in response to heat waves, but also in response to daily excursions of temperature [4]. While fewer original studies have focused on morbidity, a recent review of the literature has found that ambient temperature has significant effects on both total and cause-specific morbidity, including cardiovascular and respiratory hospital visits [7].

Some recent reviews have focused on temperature impacts among the elderly population, due to the elevated risks of mortality and morbidity in this age group. Åström and colleagues reported strong and globally consistent relationships between heat exposure and mortality among the elderly [8]. Yu et al. carried out a meta-analysis of recent mortality studies, finding a $2-5 \%$ increase in all-cause mortality for $1{ }^{\circ} \mathrm{C}$ increase during heat exposures [9]. $\mathrm{Xu}$ and colleagues reviewed evidence of the impact of ambient temperature on children's health, finding increased sensitivity to ambient temperatures, compared to adults, and a high risk of heat-related mortality in children under one year of age [10]. Occupational heat exposure has also received increasing attention in the literature, and a recent review article has found that workplace heat exposure may pose a risk of heat stress for manual workers [11].

Assessment of future temperature-related morbidity and mortality is of particular relevance in light of the projected rise in global average temperatures under a changing climate [3]. A review summarizing the findings from studies assessing future mortality impacts concluded that climate change is likely to result in increased heat-related mortality [12]. However, projecting future heat-related health impacts has been hampered by lack of data on how exposure-response functions will change in the future, due to autonomous and/or planned adaptation.

\section{Review of Recent Mortality Literature}

While a range of exposure metrics have been used to quantify the effects of temperature on mortality, recent evidence suggests that the choice of metric has little influence on epidemiologic findings. Most studies have used daily mean, minimum, or maximum temperature, or composite indices of temperature and humidity, such as the Heat Index or apparent temperature and the Humidex. Other exposure metrics such as the Temporal Synoptic Index and Spatial Synoptic Index are based on the Synoptic Climatological Classification [13] and include measures of wind speed, barometric pressure, cloud cover, and others. In a study of various exposure metrics, including mean, minimum and maximum temperature, as well as apparent temperature and the Humidex, Barnett and colleagues concluded that all of the metrics were highly correlated and that not one of them had a better predictive ability than any other [14]. In an analysis of heat-related mortality in New York City, various exposure metrics were also found to perform similarly as predictors of heat-related mortality [15]. Therefore, there is an argument for converging to the consistent use of a small number of simple metrics.

It is important to note, however, that estimates of heatrelated mortality do depend on the underlying definition of heat-related deaths. Government reports on heat-related deaths are often based on counting deaths that have been listed on death certificates as specifically heat-related (heat-stroke or hyperthermia). This approach does have the advantage of enabling rapid surveillance. However, since heat-related deaths are often under-reported, the enumeration of deaths directly attributable to heat is likely to significantly underestimate the actual effect size and is rarely utilized in epidemiology studies. The magnitude of this underestimate has not yet been well quantified. Most epidemiologic studies follow a more comprehensive approach that estimates the total burden of heat-related mortality based on a statistical analysis of deaths for large cause categories or all causes in relation to observed temperatures.

The impacts of heat on mortality can be assessed in the context of specific heat wave episodes or by analyzing the relationship between elevated temperatures and mortality over long periods of time. Studies utilizing the first approach assess the impacts of temperature on mortality during specific heat waves [16, 17], and compare this to data from periods of normal temperatures. Data from such studies can be helpful for improving the preparedness of communities to deal with extreme heat. The second approach involves regression analysis of long records of daily deaths vs. temperature in a city, while controlling for temporal confounders such as trends, seasonal cycles, day of week patterns, and sometimes air pollution. The derived exposure-response functions can be used to quantify the excess mortality that occurs above arbitrarily chosen threshold temperatures. This approach provides a comprehensive assessment of the heat-mortality relationship at a particular location and can be used to characterize changing effects over time. In addition, the location-specific heat-mortality response functions can be used to estimate potential future impacts of heat under different climate change scenarios. 
Mortality displacement or harvesting refers to the phenomenon of deaths occurring as a result of environmental exposure among physically susceptible individuals who would have died several days later if the environmental exposure in question has not occurred [4]. The evidence of harvesting in the heat-health domain has been inconclusive to-date. One study found patterns of mortality displacement to be dependent upon population characteristics, with London having the highest mortality displacement followed by Sao Paolo and Delhi [18]. Short-term mortality displacement resulting from the 2003 European heat wave was relatively small [17]. A recent study in California did not find evidence of mortality displacement [19].

Recent studies have added to our understanding of the characteristics that confer increased risk in response to elevated temperatures (i.e., effect modifiers). Studies suggest increased risks for women [20-22], for individuals with no education or living in low socio-economic districts [21, 22], and for older age [20, 21, 23, 24]. Recent evidence has also highlighted cardiovascular and respiratory deaths as being especially responsive to heat extremes [22, 25].

Although we focus on heat in the present review, it is important to note that in the context of climate change, it is also useful to consider how cold-related health effects may change in a warming climate. Evaluating cold effects is of value to public health and climate adaptation planning. The epidemiologic analysis of cold impacts has been hampered to date by problems of confounding by seasonal effects. This is especially problematic when multi-week distributed lags of cold temperatures are used as the temperature exposure metric, since such exposure definitions are strongly counfounded by season. Elevated mortality in winter is driven largely by respiratory infections and associated cardivascular sequelae. Using a two-day lag of cold temperatures, Li and colleagues projected substantial increases of net annual temperaturerelated mortality in New York City across a wide range of climate models and scenarios [26]. A few other studies that have quantified both heat- and cold-related mortality found that the increases in heat-related mortality may be offset by decreases in cold-related mortality in some cities [27-29].

Numerous studies have investigated the relationship between high ambient temperature and mortality in recent years. While previous literature focused on heat impacts mainly in North American and Western European populations, a growing number of studies have recently been reported in other parts of the world, particularly Asia [21, 22, 30-32], and Australia [23,33]. Much of the recent heat-mortality literature has focused on identifying and quantifying a "heat wave" effect above and beyond impacts of single-day temperature excursions.

Two multi-city studies have quantified the impact of heat waves (after accounting for single-day temperature risks) in the USA. Anderson and Bell analyzed the impacts of heat waves, defined as two or more days with temperature above the 95 th percentile, in 43 communities in the USA [34•]. The study found that mortality increased $3.74 \%$ during heat wave days vs. non-heat wave days nationally, and that mortality risk was higher for longer, more intense and early season heat waves. Barnett and colleagues examined the mortality impacts of heat waves lasting two or more days in 99 US cities and using various temperature thresholds between the 95th and 99th city-specific percentile [35]. Heat waves were found to generally increase mortality risk, particularly for the highest heat threshold. Increases in deaths associated with cold waves were also investigated but were found to be smaller and not statistically significant.

The EuroHEAT project in nine European cities (Athens, Barcelona, Budapest, London, Milan, Munich, Paris, Rome, Valencia) concluded that, not considering the 2003 heat wave, mortality during heat wave days increased between $7.6 \%$ in Munich and $33.6 \%$ in Milan among people over 65 years [20]. Other studies reported increased mortality during heat waves in Berlin, Germany [24]; the Castile La Mancha region of Spain [36]; Moldova [37]; and Croatia [38]. A study in Catalonia, Spain reported a $19 \%$ increase in mortality after three consecutive hot days [25]. Son and colleagues examined the effect of heat waves on mortality in seven Korean cities and found an overall increase in mortality of $4.1 \%$ on heat wave days vs. non-heat wave days, with the highest $8.4 \%$ increase reported in Seoul [21].

Several studies reported mortality associated with specific heat wave episodes: a $13 \%$ increase in mortality during a 2011 heat wave in Sydney [23]; 41 \% increase during a 2010 heat wave in in Harbin, China [32]; and 75 excess deaths during a 2004 heat wave in Brisbane, Australia [33].

In a study of England and Wales, Armstrong and colleagues found a consistent increase in mortality on the hottest days with region-specific temperature thresholds of around the $93 \mathrm{rd}$ percentile, and overall mortality increase of $2.1 \%$ per each ${ }^{\circ} \mathrm{C}$ [39]. Rocklov at al. found that persistent exposure to extremely high temperatures in Stockholm County, Sweden was associated with additional mortality, with the risk increasing significantly for every day of additional exposure [40].

Sung et al., reported in 2013 that daily mean heat indices above the 95th percentile were associated with increased morality risk ratios in six Taiwanese cities. In Chiang Mai, Thailand, the relative risk of non-external mortality at the 99th percentile vs. the 75th percentile of temperature was 1.11 [31]. In Hong Kong, $1.8 \%$ increase in mortality was observed per $1{ }^{\circ} \mathrm{C}$ increase in temperature [22]. In Tianjin, China, a $2 \%$, $3 \%, 2.8 \%$, and $3.4 \%$ increase in non-accidental, cardiopulmonary, cardiovascular, and respiratory deaths, respectively, was observed per $1{ }^{\circ} \mathrm{C}$ increase in mean temperature above the hot thresholds. Across five Chinese cities, ischemic heart disease mortality increased by $18 \%$ at the 99 th percentile of temperature compared to the 90th [30]. 
New evidence on population-level adaptation to heat has also emerged from various locations. One study found temperature-related mortality, especially during late summer, to be decreasing in Seoul [41]. Another study attributed the observed reduction in heat impact on mortality in Italy to variations in the summer temperature distributions, as well as the adaptation measures introduced after the 2003 European heat wave [42•]. In analyses encompassing over 100 years of temperature and mortality data, Ekamper and colleagues and Åström and colleagues reported declining trends in heatrelated mortality in the Netherlands [43] and Sweden [44•], respectively. It is not yet clear to what extent these decreasing trends in heat effects reflect unplanned, autonomous adaptation factors, and to what extent they may reflect planned adaptation strategies. This is an important area for future research.

\section{Review of Recent Morbidity Literature}

In comparison to studies on heat-related mortality, studies on heat-related morbidity are less abundant for several reasons. This is related in part to the more ready availability of death counts in many cities around the world. It may also reflect to some extent the epidemiology of extreme heat, which often involves impacts on homebound elderly persons who may not be able to seek medical care before succumbing to heat stroke. Still, there has been a recent increase in heat-related morbidity studies in the literature, based on outcomes including hospital admissions, emergency room visits, ambulance dispatches, and others. Several studies reported increases in emergency department visits and/or ambulance calls for heat-related illnesses during or after increases in ambient temperature in Australia $[23,45,46]$, Canada [47, 48], and in parts of the USA $[49,50]$.

Studies are increasingly assessing cause-specific hospital admissions or emergency department visits. The following section highlights several of the common outcomes associated with heat exposure. Understanding the level of heat exposure, the consequent health impacts, and vulnerable subpopulations is critical in preparing for future extreme heat events and adaptation planning.

Heat can aggravate chronic respiratory diseases such as asthma and chronic obstructive pulmonary diseases. In Brisbane, Australia, a $9.5^{\circ} \mathrm{C}$ increase in temperature above $29^{\circ} \mathrm{C}$ significantly increased ambulance attendances for respiratory effects for all ages, and those over 75 years had a much greater risk [51]. In New York City, when increases in temperature and apparent temperature exceeded 28.9 degrees and 31.7 degrees, respectively, respiratory hospital admissions increased by $2.1-2.7 \%$ on the same day [52]. More broadly in the USA, high outdoor heat was associated with respiratory hospitalizations among Medicare beneficiaries [53].
Pre-existing cardiovascular diseases can be exacerbated by exposure to heat. In California, increased apparent temperature increased emergency room visits for ischemic heart disease and stroke [54]. In Quebec, Canada, men and women between ages 45 to 65 years were surprisingly reported to be at greater risk of hospitalization due to ischemic heart disease, compared to those 65 years and older, during the summer. However, a greater total number of hospitalizations were recorded for those 65 and over, early in the summertime [55]. In Melbourne, Australia, hospitalizations for acute myocardial infarctions for those between ages 55 to 64 increased significantly on days exceeding $30^{\circ} \mathrm{C}$ [56]. During the 2009 heat wave in Adelaide, Australia, hospital admissions and emergency department visits for ischemic heart disease increased significantly for those between ages 15 to 64 years $[57,58]$.

While the elderly are clearly an important vulnerable population group, recent literature indicates the fetus is also at risk of heat impacts from maternal heat exposure during pregnancy. In California, a $5.6{ }^{\circ} \mathrm{C}$ increase in weekly average apparent temperature was associated with a significant increase in preterm deliveries [59•]. In Brisbane, Australia, infants aged 0 4 years were at greater risk of emergency department admissions for intestinal infectious diseases, respiratory, endocrine, nutritional, and metabolic diseases [60], as well as for asthma [61].

Other less studied, but critical, health outcomes of heat exposure include mental health effects. Having a mental disorder itself could put the individual at risk for heat-related morbidities, such as through thermoregulatory dysfunctions commonly associated with schizophrenia. Further, heat causes undesirable side effects from psychiatric medications [62]. In Toronto, Canada, higher daily mean temperature was associated with an increase in emergency department visits for schizophrenia, mood disorders (depression, mania, and bipolar disorder), and neurotic disorders (anxiety, panic, and stress disorders) [63]. There is also some evidence for renal morbidities as well from a study on the 2009 heat wave in Adelaide, Australia [57, 58], and in California [54].

Heat exposure in the workplace concerns both outdoor and indoor workers. Health impacts include acute heat-related illnesses such as dehydration, heat stroke, fatigue, nausea, and loss of coordination, as well as chronic effects such as cardiovascular and respiratory diseases and mental health problems [11]. In Thailand, nearly $20 \%$ of a large national cohort of full-time workers, of which $19 \%$ were physical jobs and $81 \%$ were office jobs respectively, experienced heat stress. Heat stress was significantly associated with poor overall health as well as psychological distress, and was more common among laborers and male workers [64]. Specific types of workers at risk include those in agriculture, construction, mining, military, and in manufacturing industries working around heat-generating machines [11]. 


\section{Implications for Adaptation Planning}

Public health adaptation to climate change encompasses strategies aimed at reducing adverse health impacts or enhancing resilience in response to observed or anticipated changes [65]. Although the mechanisms of public health adaptation to heat are yet to be well understood, several studies have demonstrated that population mortality responses to high temperatures have tended to decline over time [43, 44•, 66, 67]. Heat adaptation is a complex process that may involve physiological, behavioral, and technological components over various time scales. While the reasons for these trends remain uncertain, social advances such as improved means of communication and increased prevalence of air conditioning are likely to play some role.

A wide range of adaptation strategies, both short-term and long-term, can facilitate the heat adaptation process. Adaptation can be defined as autonomous or planned, as well as reactive or anticipatory actions [68]. Autonomous or spontaneous adaptation occurs without coordinated planning in individuals or communities, and is usually reactive by nature. Planned adaptation, on the other hand, usually involves deliberate policy actions that are based on anticipated climate risks. For instance, increased use of air conditioning during a heat wave episode is an example of an autonomous adaptation. The implementation of a heat warning system is, however, an example of planned adaptation. Since autonomous adaptation may not be able to adequately address the health challenges posed by a changing climate, the need for planned adaptation is being globally increasingly recognized.

Increased awareness of heat impacts on mortality and morbidity has led to the introduction of heat adaptation interventions in many urban areas around the world. Most of these interventions are focused on heat preparedness and response during heat wave episodes and include heat warning systems, AC programs, 'heat lines,' cooling centers, and educational programs targeted at vulnerable subgroups. Due to the many interconnections between climate change, the built environment [69], and public health, initiatives aimed at improving urban land use, city planning, and building design may be included as a long-term strategy. Many countries have implemented heat-health adaptation plans as a component of broader climate action plans [70•]. Yet, despite the rapid adoptions of such interventions, there is insufficient evidence of their effectiveness [42•, 71, 72]. More comprehensive methodologies need to be developed for the assessment of the effectiveness of heat interventions [73, 74].

Epidemiology can play a key role in building the knowledge base to develop, implement, and evaluate effective adaptation interventions aimed at reducing heat impacts on public health. In Table 1, we list several ways in which epidemiologic methods will be critical in this process, and where new knowledge can play an especially significant role in future adaptation planning.

Since the impacts of heat are location-specific, and appear to change over time, locally-derived heat-health response functions, estimated from recent data, are essential for assessing temperature-mortality and morbidity impacts, and utilizing these assessments in urban adaptation planning. Identifying accurate locally-relevant temperature thresholds, above which adverse impacts are observed, is particularly important for issuing heat warnings and timely communication with vulnerable populations.

Recent developments in syndromic surveillance systems have demonstrated their capacity for the rapid detection of
Table 1 Epidemiologic research needs in support of adaptation planning

\begin{tabular}{|c|c|}
\hline Research need & Description \\
\hline Documenting adaptation trends & $\begin{array}{l}\text { Assessing trends in heat-health response over time, based on local } \\
\text { data, can provide valuable insight into heat adaptation trends }\end{array}$ \\
\hline $\begin{array}{l}\text { Evaluating the effectiveness } \\
\text { of planned interventions }\end{array}$ & $\begin{array}{l}\text { Consistent methods are needed for evaluating the effectiveness } \\
\text { of heat-health interventions }\end{array}$ \\
\hline Syndromic surveillance & $\begin{array}{l}\text { Real-time surveillance of heat-related health syndromes can provide } \\
\text { data of use in resource mobilization during heat events }\end{array}$ \\
\hline $\begin{array}{l}\text { Targeting interventions to } \\
\text { those most vulnerable }\end{array}$ & $\begin{array}{l}\text { Heat vulnerability maps need to be developed that take into account } \\
\text { local, fine-scaled health outcome data }\end{array}$ \\
\hline Projecting future health impacts & $\begin{array}{l}\text { Exposure response functions and adaptation assumptions are } \\
\text { needed for assessing impacts of future climate scenarios }\end{array}$ \\
\hline $\begin{array}{l}\text { Health relevance of spatial } \\
\text { patterns of exposure }\end{array}$ & $\begin{array}{l}\text { Recent evidence suggests that outdoor temperatures can vary } \\
\text { substantially within urban areas depending on local land use. } \\
\text { Understanding implications for health will be important. }\end{array}$ \\
\hline Assessment of personal exposures & $\begin{array}{l}\text { Virtually no data are yet available assessing actual exposures } \\
\text { of vulnerable populations during heat events. }\end{array}$ \\
\hline Quantifying the impacts of power failures & $\begin{array}{l}\text { Epidemiology is needed for quantifying the health impacts of heat } \\
\text { events that coincide with power failures }\end{array}$ \\
\hline
\end{tabular}


heat-related emergency department visits and ambulance calls, and ultimately preventing heat-related adverse outcomes [23, 75-80]. Systematic collection of health indicators during heat events is important for both evaluating their impact and monitoring heat adaptation over time. Long records of syndromic surveillance data can also greatly facilitate the development and improvement of interventions targeted at reducing heat-related mortality and morbidity among vulnerable subgroups.

Vulnerability mapping is another emerging area of research that can provide valuable information for use in preventing heat-related morbidity and mortality in vulnerable populations. Characterizing neighborhood-level heat vulnerability brings together evidence from epidemiological studies on individual level susceptibility factors and information on neighborhood characteristics [81-83], thus enabling more informed preventive actions.

Finally, multidisciplinary and interdisciplinary research and collaboration across sectors is necessary to better assess the health benefits of alternative adaptation investments in heat warning and response systems, education and health communications, and long term architecture and urban planning. However, the information necessary for making informed adaptation decisions remains limited. Filling this data gap will require the development and ongoing support of research partnerships involving epidemiologists, climate scientists, and local stakeholders such as health department professionals.

\section{Conclusions}

Recent epidemiologic findings on heat-related health impacts have reinforced our understanding of the mortality impacts of extreme heat and have shown a range of impacts on morbidity outcomes, including cardiovascular, respiratory, and mental health responses. Evidence on temporal trends towards decreasing exposure-response is documenting population adaptation. In the meantime, cities are actively engaged in the development of heat adaptation plans to reduce future health impacts. Epidemiologic research on local heat-health responses can play a central role in adaptation planning for heat, to reduce adverse health outcomes among vulnerable populations, and to evaluate the effectiveness of interventions. Such research will be most impactful if it arises from partnerships involving epidemiologists, climate scientists, and local stakeholders.

Acknowledgements This work was supported by Center Grant \#P30 ES009089 from the National Institute of Environmental Health Sciences, and from the NOAA-funded Consortium for Climate Risks in the Urban Northeast (\#NA10 OAR4310212).

\section{Compliance with Ethics Guidelines}

Conflict of Interest EP Petkova declares no conflicts of interest. $\mathrm{H}$ Morita declares no conflicts of interest.
PL Kinney serves as a consultant for the USEPA and Natural Resources Defense Council.

Human and Animal Rights and Informed Consent This article does not contain any studies with human or animal subjects performed by any of the authors.

\section{References}

Papers of particular interest, published recently, have been highlighted as:

- Of importance

1. National Weather Service. Natural Hazard Statistics. 2014 Jan 7 [cited 2014 Mar 3]; Available from: http://www.nws.noaa.gov/om/ hazstats.shtml.

2. Confalonieri U, et al. Human health. Climate change 2007: impacts, adaptation and vulnerability. Contribution of working group II to the fourth assessment report of the intergovernmental panel on climate change, 2007.

3. IPCC. The physical science basis. Contribution of working group I to the fifth assessment report of the intergovernmental panel on climate change. In: Stocker TF et al., editors. Climate change 2013. Cambridge: Cambridge University Press; 2013. p. 1535.

4. Basu R. High ambient temperature and mortality: a review of epidemiologic studies from 2001 to 2008. Environ Health. 2009;8(1):40.

5. Basu R, Samet JM. Relation between elevated ambient temperature and mortality: a review of the epidemiologic evidence. Epidemiol Rev. 2002;24(2):190-202.

6. Kovats RS, Hajat S. Heat stress and public health: a critical review. Annu Rev Public Health. 2008;29:41-55.

7. Ye $\mathrm{X}$ et al. Ambient temperature and morbidity: a review of epidemiological evidence. Environ Health Perspect. 2012;120(1):19.

8. Astrom DO, Forsberg B, Rocklov J. Heat wave impact on morbidity and mortality in the elderly population: a review of recent studies. Maturitas. 2011;69(2):99-105.

9. $\mathrm{Yu} \mathrm{W}$ et al. Daily average temperature and mortality among the elderly: a meta-analysis and systematic review of epidemiological evidence. Int J Biometeorol. 2012;56(4):569-81.

10. $\mathrm{Xu} \mathrm{Z}$ et al. Impact of ambient temperature on children's health: a systematic review. Environ Res. 2012;117:120-31.

11. Xiang J, et al. Health impacts of workplace heat exposure: an epidemiological review. Ind Health. 2013.

12. Huang $\mathrm{C}$ et al. Projecting future heat-related mortality under climate change scenarios: a systematic review. Environ Health Perspect. 2011;119(12):1681-90.

13. Kalkstein LS et al. A new spatial synoptic classification: application to air mass analysis. Int J Climatol. 1996;16(9):983-1004.

14. Barnett AG, Tong S, Clements A. What measure of temperature is the best predictor of mortality? Environ Res. 2010;110(6):604-11.

15. Metzger KB, Ito K, Matte TD. Summer heat and mortality in New York City: how hot is too hot? Environ Health Perspect. 2010;118(1):80-6.

16. Semenza JC et al. Excess hospital admissions during the July 1995 heat wave in Chicago. Am J Prev Med. 1999;16(4):269-77.

17. Le Tertre A et al. Impact of the 2003 heatwave on all-cause mortality in 9 French cities. Epidemiology. 2006;17(1):75-9.

18. Hajat $\mathrm{S}$ et al. Mortality displacement of heat-related deaths: a comparison of Delhi, Sao Paulo, and London. Epidemiology. 2005;16(5):613-20. 
19. Basu R, Malig B. High ambient temperature and mortality in California: exploring the roles of age, disease, and mortality displacement. Environ Res. 2011;111(8):1286-92.

20. D'Ippoliti D et al. The impact of heat waves on mortality in 9 European cities: results from the EuroHEAT project. Environ Health. 2010;9:37.

21. Son JY et al. The impact of heat waves on mortality in seven major cities in Korea. Environ Health Perspect. 2012;120(4):566-71.

22. Chan EY et al. A study of intracity variation of temperature-related mortality and socioeconomic status among the Chinese population in Hong Kong. J Epidemiol Community Health. 2012;66(4):322-7.

23. Schaffer A et al. Emergency department visits, ambulance calls, and mortality associated with an exceptional heat wave in Sydney, Australia, 2011: a time-series analysis. Environ Health. 2012;11(1):3.

24. Gabriel KM, Endlicher WR. Urban and rural mortality rates during heat waves in Berlin and Brandenburg, Germany. Environ Pollut. 2011;159(8-9):2044-50.

25. Basagana $X$ et al. Heat waves and cause-specific mortality at all ages. Epidemiology. 2011;22(6):765-72.

26. Li T, Horton RM, Kinney PL. Projections of seasonal patterns in temperature-related deaths for Manhattan. New York: Nature Climate Change; 2013.

27. Guest C, et al. Climate and mortality in Australia: retrospective study, 1979-1990, and predicted impacts in five major cities in 2030. 1999.

28. Martens WJ. Climate change, thermal stress and mortality changes. Soc Sci Med. 1998;46(3):331-44.

29. Martin SL et al. Climate change and future temperature-related mortality in 15 Canadian cities. Int J Biometeorol. 2012;56(4): 605-19.

30. Guo Y et al. Extremely cold and hot temperatures increase the risk of ischaemic heart disease mortality: epidemiological evidence from China. Heart. 2013;99(3):195-203.

31. Guo Y, Punnasiri K, Tong S. Effects of temperature on mortality in Chiang Mai city, Thailand: a time series study. Environ Health. 2012;11:36.

32. Lan L et al. Increased mortality during the 2010 heat wave in Harbin, China. EcoHealth. 2012;9(3):310-4.

33. Tong S, Wang XY, Barnett AG. Assessment of heat-related health impacts in Brisbane, Australia: comparison of different heatwave definitions. PLoS One. 2010;5(8):e12155.

34. Anderson GB, Bell ML. Heat waves in the USA: mortality risk during heat waves and effect modification by heat wave characteristics in 43 US communities. Environ Health Perspect. 2011;119(2): 210. Documents and compares the effects of heat waves on mortality across the U.S., as well as effect modification by heat wave characteristics. Finds higher mortality risk from intense or longer heat waves, as well as heat waves occurring during the summer and more pronounced impacts in the U.S. Northeast and Midwest compared to the South.

35. Barnett AG et al. Cold and heat waves in the United States. Environ Res. 2012;112:218-24.

36. Montero JC et al. Influence of local factors in the relationship between mortality and heat waves: Castile-La Mancha (19752003). Sci Total Environ. 2012;414:73-80.

37. Corobov R et al. Heat-related mortality in Moldova: the summer of 2007. Int J Climatol. 2013;33(11):2551-60.

38. Zaninović K, Matzarakis A. Impact of heat waves on mortality in Croatia. Int J Biometeorol. 2013:1-11.

39. Armstrong BG et al. Association of mortality with high temperatures in a temperate climate: England and Wales. J Epidemiol Community Health. 2011;65(4):340-5.

40. Rocklov J, Ebi K, Forsberg B. Mortality related to temperature and persistent extreme temperatures: a study of cause-specific and agestratified mortality. Occup Environ Med. 2011;68(7):531-6.
41. Ha J, Kim H. Changes in the association between summer temperature and mortality in Seoul, South Korea. Int J Biometeorol. 2013;57(4):535-44.

42. Schifano $\mathrm{P}$ et al. Changes in the effects of heat on mortality among the elderly from 1998-2010: results from a multicenter time series study in Italy. Environ Health. 2012;11(1):58. Studies elderly mortality impact before and after an heat adaptation intervention during a heat wave and saw a positive outcome of reduction in elderly mortality.

43. Ekamper $\mathbf{P}$ et al. 150 years of temperature-related excess mortality in the Netherlands. Demogr Res. 2009;21(14):385-426.

44. Aström DO, et al. Acute fatal effects of short-lasting extreme temperatures in Stockholm, Sweden: evidence across a century of change. Epidemiology (Cambridge, Mass.). 2013. Quantifies temperature effects over a century-long period finding that relative risk of mortality during heat extremes has declined over time, leveling off in the three most recent decades.

45. Lindstrom SJ, Nagalingam V, Newnham HH. Impact of the 2009 Melbourne heatwave on a major public hospital. Intern Med J. 2013;43(11):1246-50.

46. Williams $\mathrm{S}$ et al. Heat and health in Adelaide, South Australia: assessment of heat thresholds and temperature relationships. Sci Total Environ. 2012;414:126-33.

47. Bassil KL et al. The relationship between temperature and ambulance response calls for heat-related illness in Toronto, Ontario, 2005. J Epidemiol Community Health. 2011;65(9):829-31.

48. Bustinza R et al. Health impacts of the July 2010 heat wave in Quebec, Canada. BMC Public Health. 2013;13:56.

49. Lippmann SJ et al. Ambient temperature and emergency department visits for heat-related illness in North Carolina, 2007-2008. Environ Res. 2013;124:35-42.

50. Hartz DA et al. Climate and heat-related emergencies in Chicago, Illinois (2003-2006). Int J Biometeorol. 2012;56(1):71-83.

51. Turner LR, Connell D, Tong S. The effect of heat waves on ambulance attendances in Brisbane, Australia. Prehosp Disaster Med. 2013;28(5):482-7.

52. Lin $\mathrm{S}$ et al. Extreme high temperatures and hospital admissions for respiratory and cardiovascular diseases. Epidemiology. 2009;20(5): 738-46.

53. Anderson GB et al. Heat-related emergency hospitalizations for respiratory diseases in the Medicare population. Am J Respir Crit Care Med. 2013;187(10):1098-103.

54. Basu $\mathrm{R}$ et al. The effect of high ambient temperature on emergency room visits. Epidemiology. 2012;23(6):813-20.

55. Bayentin L et al. Spatial variability of climate effects on ischemic heart disease hospitalization rates for the period 1989-2006 in Quebec, Canada. Int J Health Geogr. 2010;9:5.

56. Loughnan ME, Nicholls N, Tapper NJ. The effects of summer temperature, age and socioeconomic circumstance on acute myocardial infarction admissions in Melbourne, Australia. Int J Health Geogr. 2010;9:41.

57. Nitschke $\mathrm{M}$ et al. Impact of two recent extreme heat episodes on morbidity and mortality in Adelaide, South Australia: a case-series analysis. Environ Health. 2011;10(1):42.

58. Mayner L, Arbon P, Usher K. Emergency department patient presentations during the 2009 heatwaves in Adelaide. Collegian. 2010;17(4):175-82.

59. Basu R, Malig B, Ostro B. High ambient temperature and the risk of preterm delivery. Am J Epidemiol. 2010;172(10):1108-17. Provides important new evidence of the association between apparent temperature and preterm delivery. Finds a significant associations for apparent temperature and preterm delivery regardless of maternal characteristics, pointing to the need of large-scale studies on the subject.

60. $\mathrm{Xu} \mathrm{Z}$, et al. Extreme temperatures and paediatric emergency department admissions. J Epidemiol Community Health. 2013. 
61. $\mathrm{Xu} \mathrm{Z}$ et al. Extreme temperatures and emergency department admissions for childhood asthma in Brisbane, Australia. Occup Environ Med. 2013;70(10):730-5.

62. Cusack L, de Crespigny C, Athanasos P. Heatwaves and their impact on people with alcohol, drug and mental health conditions: a discussion paper on clinical practice considerations. J Adv Nurs. 2011;67(4):915-22.

63. Wang $X$ et al. Acute impacts of extreme temperature exposure on emergency room admissions related to mental and behavior disorders in Toronto, Canada. J Affect Disord. 2014;155:154-61.

64. Tawatsupa B, et al. The association between overall health, psychological distress, and occupational heat stress among a large national cohort of 40,913 Thai workers. Global Health Action. 2010;3.

65. Huang $\mathrm{C}$ et al. Constraints and barriers to public health adaptation to climate change: a review of the literature. Am J Prev Med. 2011;40(2):183-90.

66. Davis RE et al. Changing heat-related mortality in the United States. Environ Health Perspect. 2003;111(14):1712.

67. Carson $\mathrm{C}$ et al. Declining vulnerability to temperature-related mortality in London over the 20th century. Am J Epidemiol. 2006;164(1):77-84.

68. IPCC. Impacts, adaptation and vulnerability. Contribution of working group II to the fourth assessment report of the intergovernmental panel on climate change. In: Parry ML et al., editors. Climate change 2007. Cambridge: Cambridge University Press; 2007. p. 976.

69. Younger $\mathrm{M}$ et al. The built environment, climate change, and health: opportunities for co-benefits. Am J Prev Med. 2008;35(5): 517-26.

70. Bittner MI, et al. Are European countries prepared for the next big heat-wave? Eur J Public Health. 2013. This paper describes and assesses the first comprehensive assessment of the development of heat preparedness planning in WHO European Region member states, as well as provide recommendations for improvements.

71. Ebi KL, et al. Heat watch/warning systems save lives: estimated costs and benefits for Philadelphia 1995-98. Bull Am Meteorol Soc. 2004;85(8).
72. Morabito $\mathrm{M}$ et al. Heat-related mortality in the Florentine area (Italy) before and after the exceptional 2003 heat wave in Europe: an improved public health response? Int J Biometeorol. 2012;56(5): 801-10.

73. Kovats S, Bickler G. Health protection and heatwaves: the need for systematic reviews. Cochrane Database Syst Rev (Online). 2012;8: ED000044.

74. Lowe D, Ebi KL, Forsberg B. Heatwave early warning systems and adaptation advice to reduce human health consequences of heatwaves. Int J Environ Res Public Health. 2011;8(12):4623-48.

75. Josseran L et al. Syndromic surveillance and heat wave morbidity: a pilot study based on emergency departments in France. BMC Med Inform Decis Mak. 2009;9(1):14.

76. Josseran L et al. Assessment of a syndromic surveillance system based on morbidity data: results from the Oscour ${ }^{\circledR}$ Network during a heat wave. PLoS One. 2010;5(8):e11984.

77. Leonardi $\mathrm{G}$ et al. Syndromic surveillance use to detect the early effects of heat-waves: an analysis of NHS direct data in England. Soz Praventivmed. 2006;51(4):194-201.

78. Mamou F, Henderson T. Analysis of heat illness using Michigan emergency department syndromic surveillance. Online J Public Health Inform. 2013;5(1).

79. Perry AG, et al. Modeling and syndromic surveillance for estimating weather-induced heat-related illness. J Environ Public Health. 2011;2011.

80. Michelozzi P et al. Surveillance of summer mortality and preparedness to reduce the health impact of heat waves in Italy. Int J Environ Res Public Health. 2010;7(5):2256-73.

81. Reid CE et al. Mapping community determinants of heat vulnerability. Environ Health Perspect. 2009;117(11):1730.

82. Rinner $\mathrm{C}$ et al. The role of maps in neighborhood-level heat vulnerability assessment for the city of Toronto. Cartogr Geogr Inf Sci. 2010;37(1):31-44.

83. Reid CE et al. Evaluation of a heat vulnerability index on abnormally hot days: an environmental public health tracking study. Environ Health Perspect. 2012;120(5):715. 